\title{
INSTALLATION OF A NEW 80 T MRP-L CONVERTER AT APERAM TIMOTEO*
}

\author{
Dr.Günther Staudinge ${ }^{1}$ \\ Marcos Sávio da Silva² \\ Alberto Walison Drumond 3 \\ Jose Eustaquio Pinto ${ }^{4}$
}

\begin{abstract}
Aperam is a global player in producing of stainless, electrical and special steel qualities. The steelmaking plant in Timoteo Brasil is equipped with one AODconverter for stainless steel and one MRPL-converter for special steel production. After almost 20 years of operation Aperam decided to exchange the existing $80 \mathrm{t}$ MRP-L converter by a new one including a new trunnion ring and a state of the art suspension system. Due to an optimized design the inner volume of the new converter could be increased which comes along with improved production. A special feature is a flange connection in the barrel section of the converter. This allowed to avoid any critical site welding and the time between shut down of the old and cold commissioning of the new converter could be done with 17 days only.

Keywords: Oxygen steelmaking; Converter steelmaking; Trunnion ring; Suspension system; Converter vessel.
\end{abstract}




\section{INTRODUCTION}

In November 2014, APERAM Timoteo awarded DANIELI for the revamping of the existing converter in Timoteo (Brazil). APERAM requested a new converter design with a maximum inner volume and minimizing the welding onsite by keeping the main dimensions like bearing distance, top and bottom level of the vessel, tilting drive, etc. unchanged.

The keys to success:

- New trunnion ring with welded pins

- Converter with increased volume from $56 \mathrm{~m}^{3}$ to $62.2 \mathrm{~m}^{3}$, this is a plus of $11 \%$

- Maintenance free converter suspension system based on the DANI-ELLA horizontal and lamella type vertical elements

- Maintaining the existing tilting drive, bearing size, bearing housings and dog house

- Avoiding welding on site by introduction of a flange connection in the barrel section of the vessel shell

- Optimized slag shields

- Keeping the delivery time to a minimum

These design features also allowed a transport of the lower part of the vessel shell already fully assembled with the trunnion ring and the suspension system. Which came along with a minimizing of the site activities and avoiding any critical welding of the vessel shell on site. Together with a very careful and detailed planning of the dismantling and erection procedure, carried out by Aperam it was possible to apply the cold commissioning of the new equipment only 17 days of erection time. Also the hot start up could be applied without any concerns and the new converter was under full production just after few heats.

The successful collaboration between APERAM Timoteo and DANIELI Linz Technology ensured that all requirements have been achieved and laying the foundation for a successful execution of the project and fast start up.

\section{CONVERTER DESIGN}

The MRP-L process is a special steelmaking process based on bottom stirring combined with oxygen top blowing. The main products are special electro- and Sisteel grades. The converter consists of top cone, barrel section, bottom cone with detachable bottom. The trunnion ring consists of a welded ring section with bolted trunnion ring pins. The suspension system is based on the classical tendon-type suspension system consisting of 4 vertical tendon type and 2 horizontal pin type elements. An overview is shown in Figure 1. 


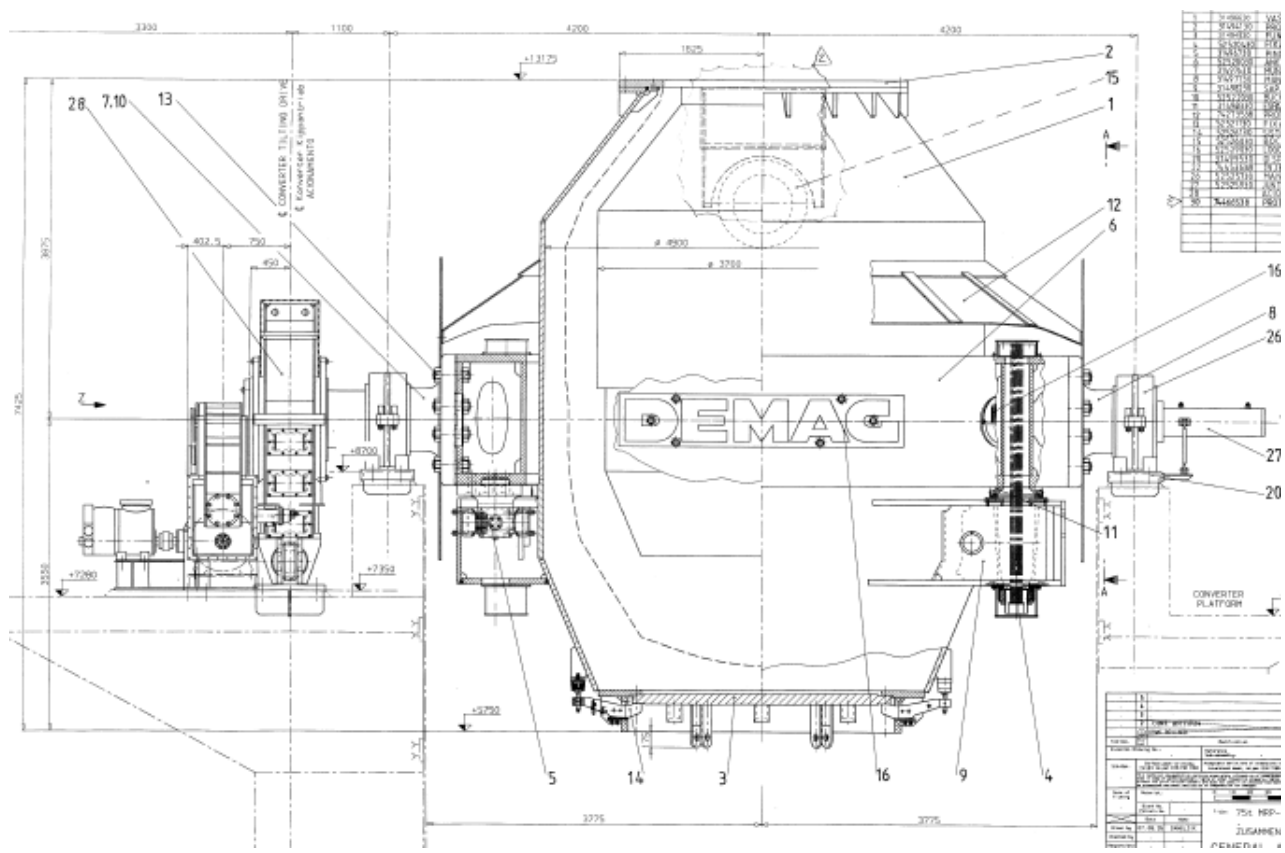

Figure 1: Overview of the existing MRP-L converter arrangement

\subsection{Boundary condition for new converter application}

As like as in classical revamping projects also here the main data of the existing converter arrangement should remain unchanged, which are:

- Trunnion ring bearing distance

- Top level of converter mouth

- Bottom level of converter bottom

- Converter mouth diameter

- Tilting circle of the converter

- Reusing of exchangeable converter bottom

Under this boundary condition the main parameter for increasing the inner volume is the barrel diameter of the converter. The key to success was the changing of the trunnion design.

\section{TRUNNION RING DESIGN}

As already mentioned one key factor for this project was the design change from bolted trunnion pins to welded ones. This allows an enlargement of the converter diameter and consequently an increase in the reaction volume

With this design change there was room for increasing the converter diameter which is the main driving factor for increasing the volume. Here the outer diameter of the converter vessel shell could be increased from $5000 \mathrm{~mm}$ to $5320 \mathrm{~mm}$. An overview of the new arrangement is shown in Figure 2. 


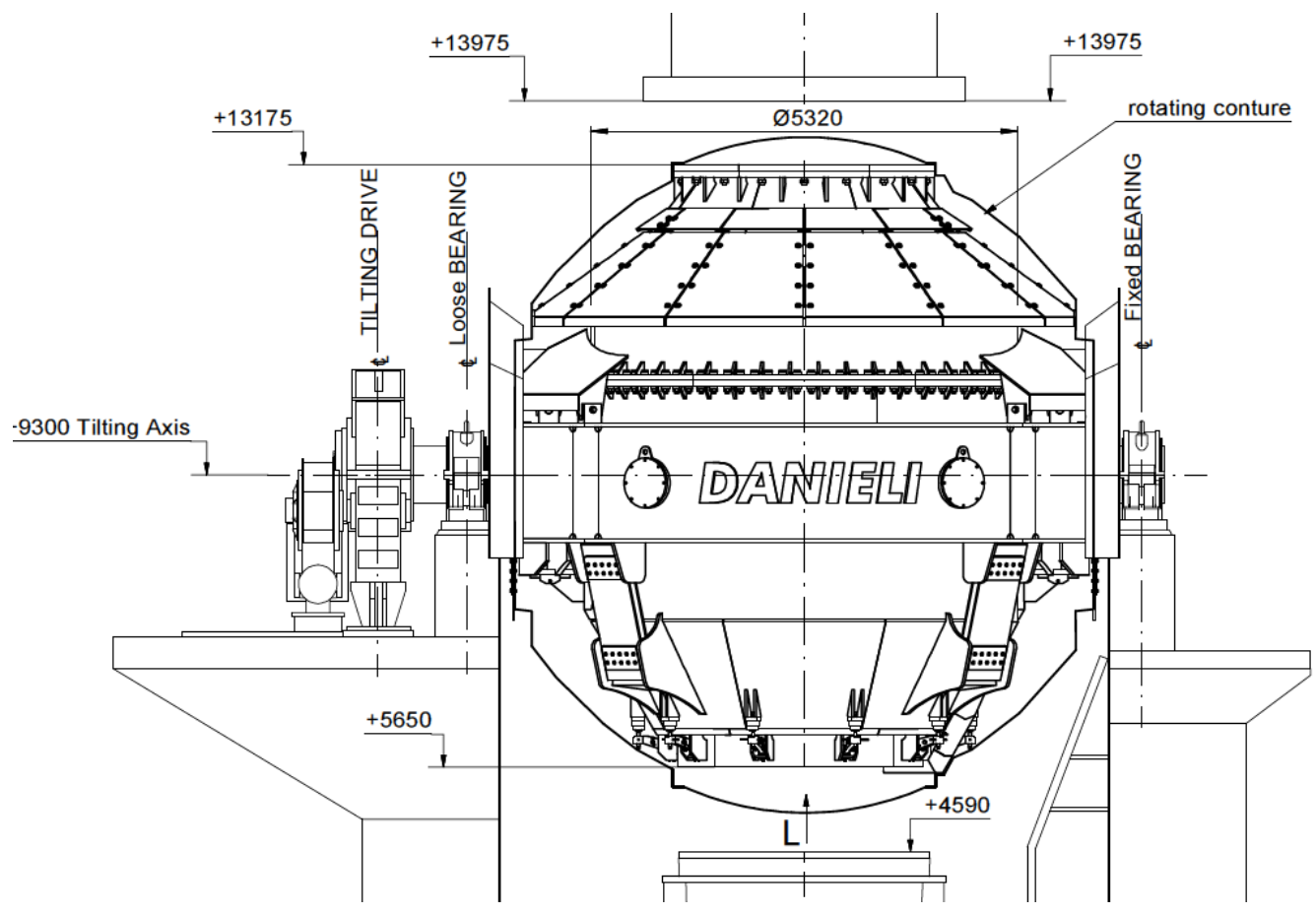

Figure 2: Overview of the new MRP-L converter arrangement

Additionally it was possible to enlarge the converter barrel height by $100 \mathrm{~mm}$. This gave finally an increase of the reaction volume (inside lining) from $56 \mathrm{~m}^{3}$ to more than $62 \mathrm{~m}^{3}$, which means and increase by approx. $11 \%$. This will have a positive effect on the process in terms of decreased blowing time as well as increased yield due to less slopping activities. A comparison is shown in Figure 3.
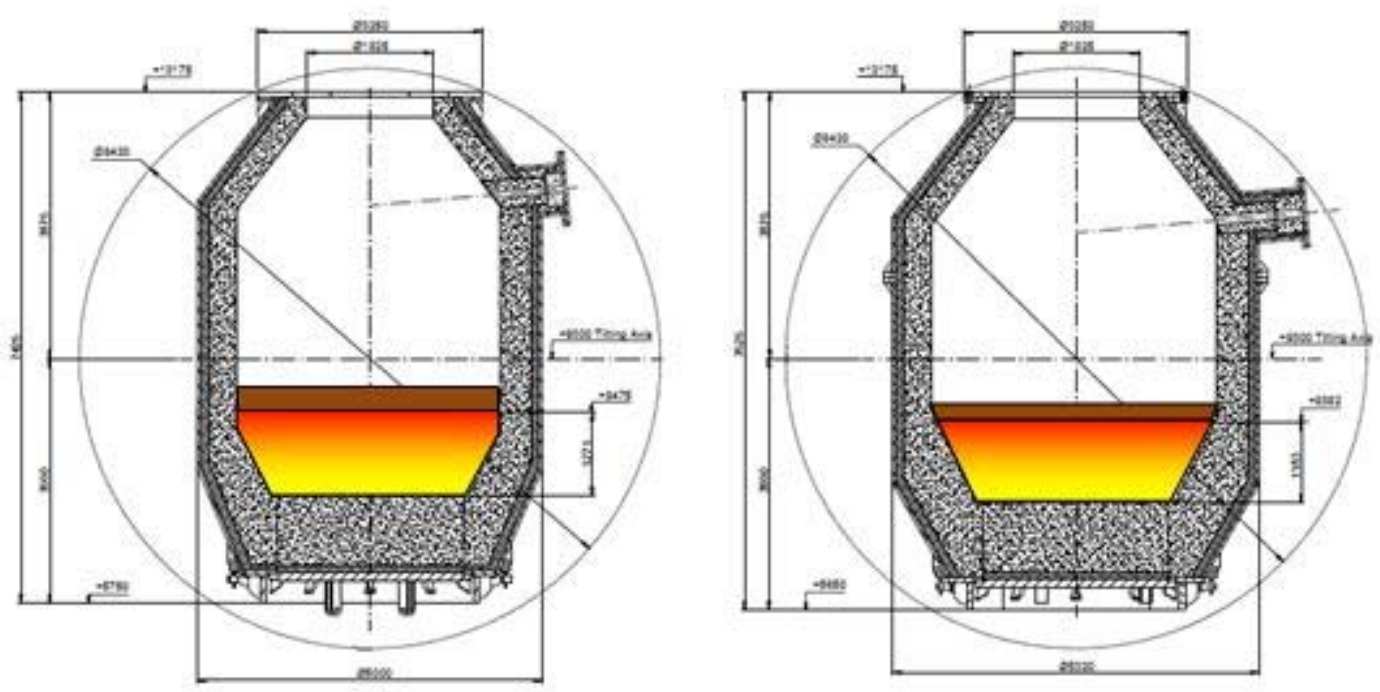

Figure 3: Comparison of existing (left) and the optimized vessel shell (right) 


\section{SUSPENSION SYSTEM}

The existing suspension system is based on 4 vertical suspension tendon elements and 2 horizontal pin type elements. The continuously increased maintenance activities for the suspension elements particularly for the horizontal elements were one of the major reasons for the converter exchange. The new suspension system is based on vertical lamella type and horizontal Daniella elements. Due to the small size of the converter the number of vertical elements could be reduced from 8 to 4 . The 2 horizontal Daniella elements are arranged directly underneath the pin axes (see Figure 4).

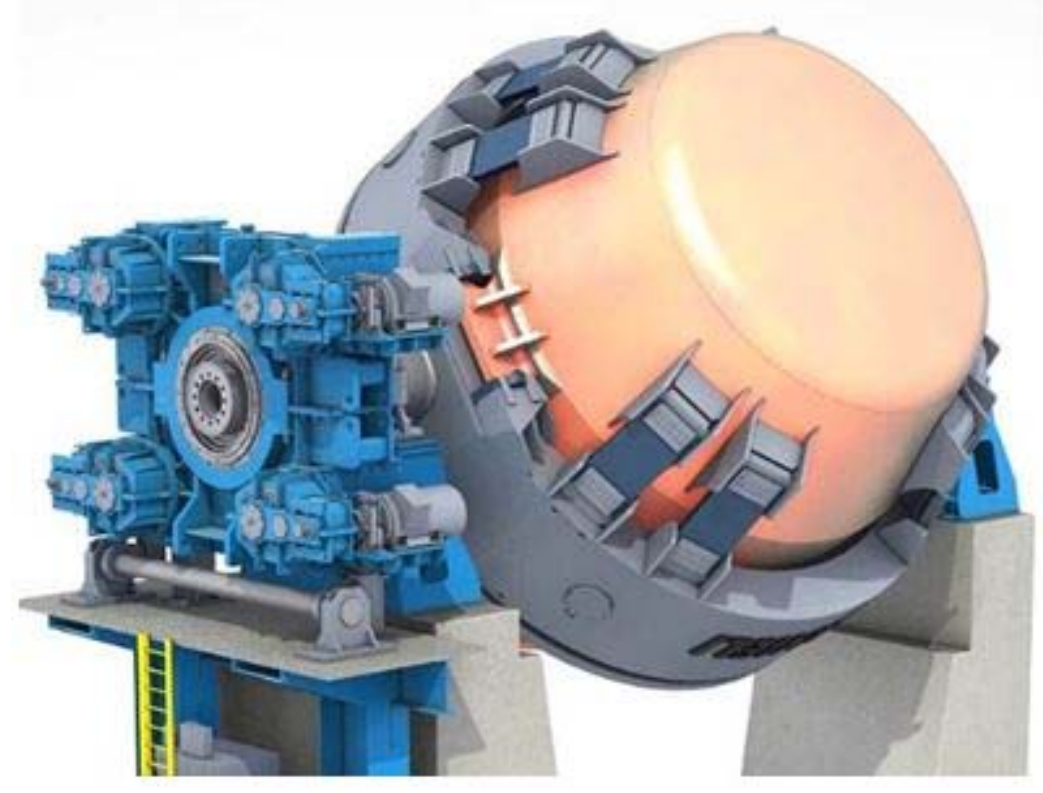

Figure 4: Principle of the DANI-ELLA suspension system (left), typical arrangement of suspension elements (right)

The application of this suspension system could reduce the weight compared to the existing one by $50 \%$.

\section{ERECTION OF CONVERTER EQUIPMENT ON SITE}

A key factor for this project was to minimize the erection activities on site such as welding due to quality reasons. A key factor for this solution was the introduction of a flange connection in the converter vessel shell. Usually such a flange is arranged between top cone and barrel section of the vessel shell. Due to the fact that there is the tap hole arranged this flange has been located underneath the tap hole. So, the flange connects a upper part of the vessel to a lower part (see Figure 5). This solution is basically similar to the classical arrangement but in any case new for converters. 


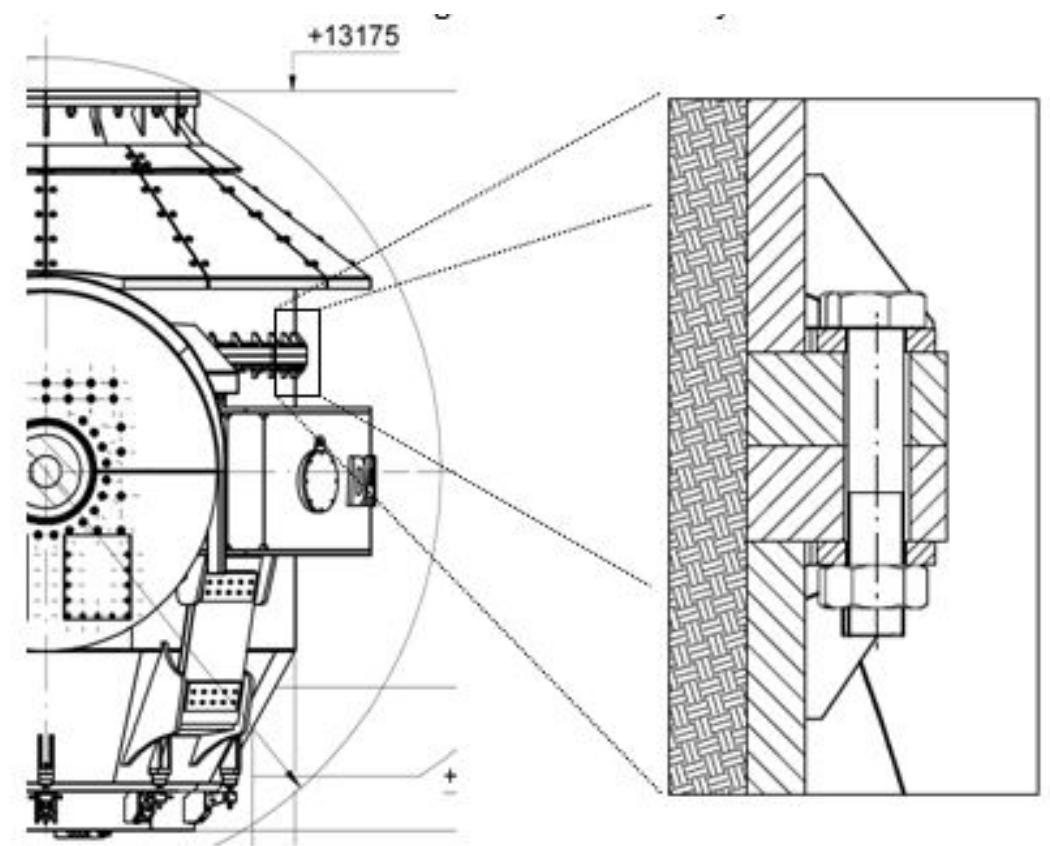

Figure 5: Arrangement of the flange connection between upper and lower part of the vessel shell (right flange details)

Taken advantage of this solution further investigation in terms of transport have been applied which finally confirmed that the complete set consisting of lower vessel shell, complete trunnion ring fully assembled with suspension system can be transported from workshop to site at Timoteo In Figure the transport as well as the pickup of the set in the plant is shown.
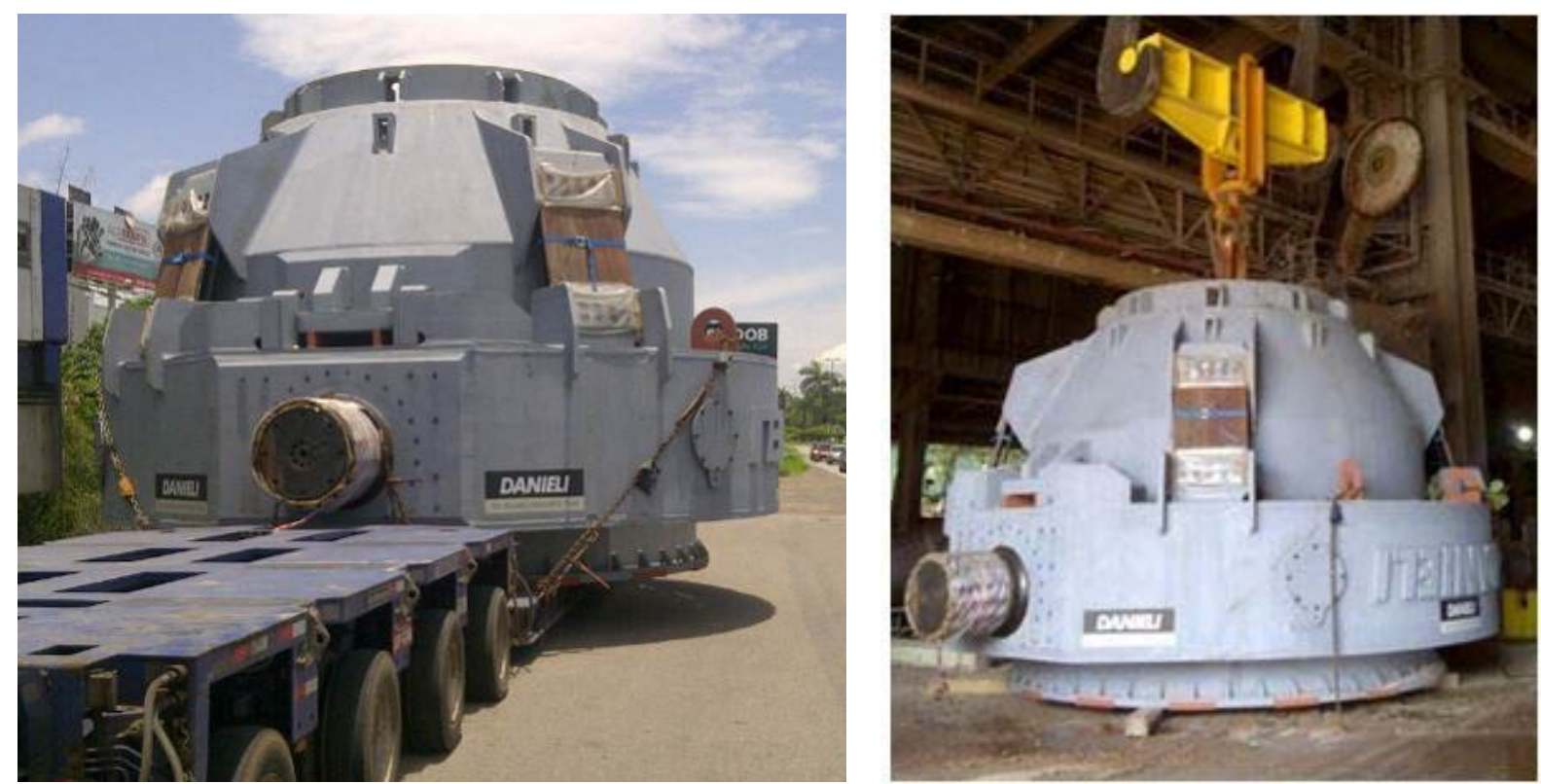

Figure 6: Transportation and pick up on site of converter lower part already fully assembled with the trunnion ring and suspension system 


\section{ERECTION PROCEDURE:}

The erection procedure itself is an extremely important part of the project and needs a very detailed investigation and planning of all the activities in order to find the optimum in terms of time and costs.

This investigation has been applied by Aperam with the assistance of Danieli in very professional way using state of the art techniques. In particular the full dismantling and erection procedure has been simulated in a full 3D and finalized in a movie which was used to have a common understanding of the process as well as coordinate all activities an very detail. Some typical screen shots are shown in Figure 6.
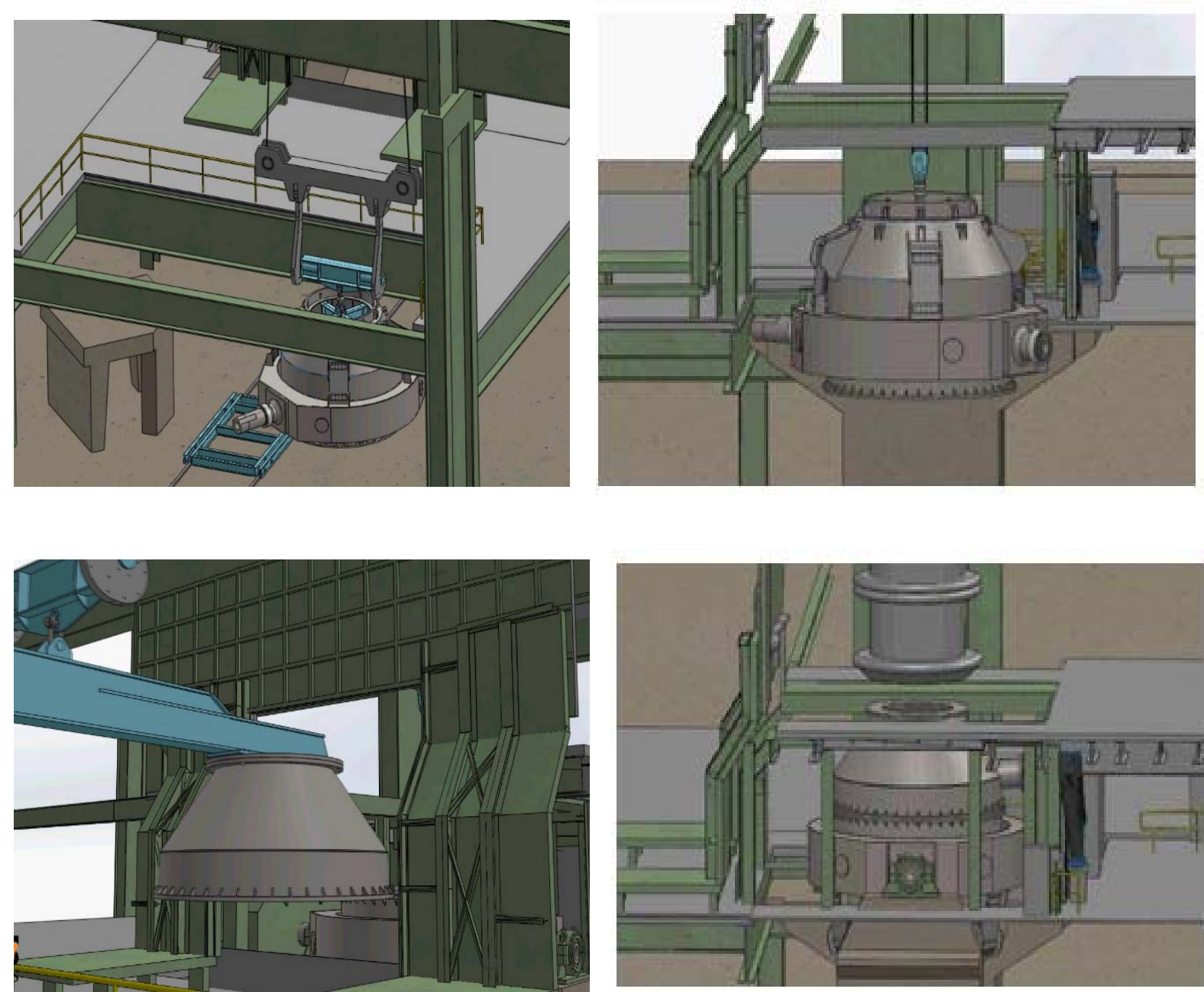

Figure 6: Some screen shots of the 3D-simulation of the erection procedure

\section{START UP}

Due to the above mentioned facts the time schedule of the project could be minimized and the hot start up has been applied within less than 13 months after signing the contract and the erection time could be minimized to 17 days only. Since 30.12.2015 the 80 t MRP-L converter is under full production (see Figure 8). 


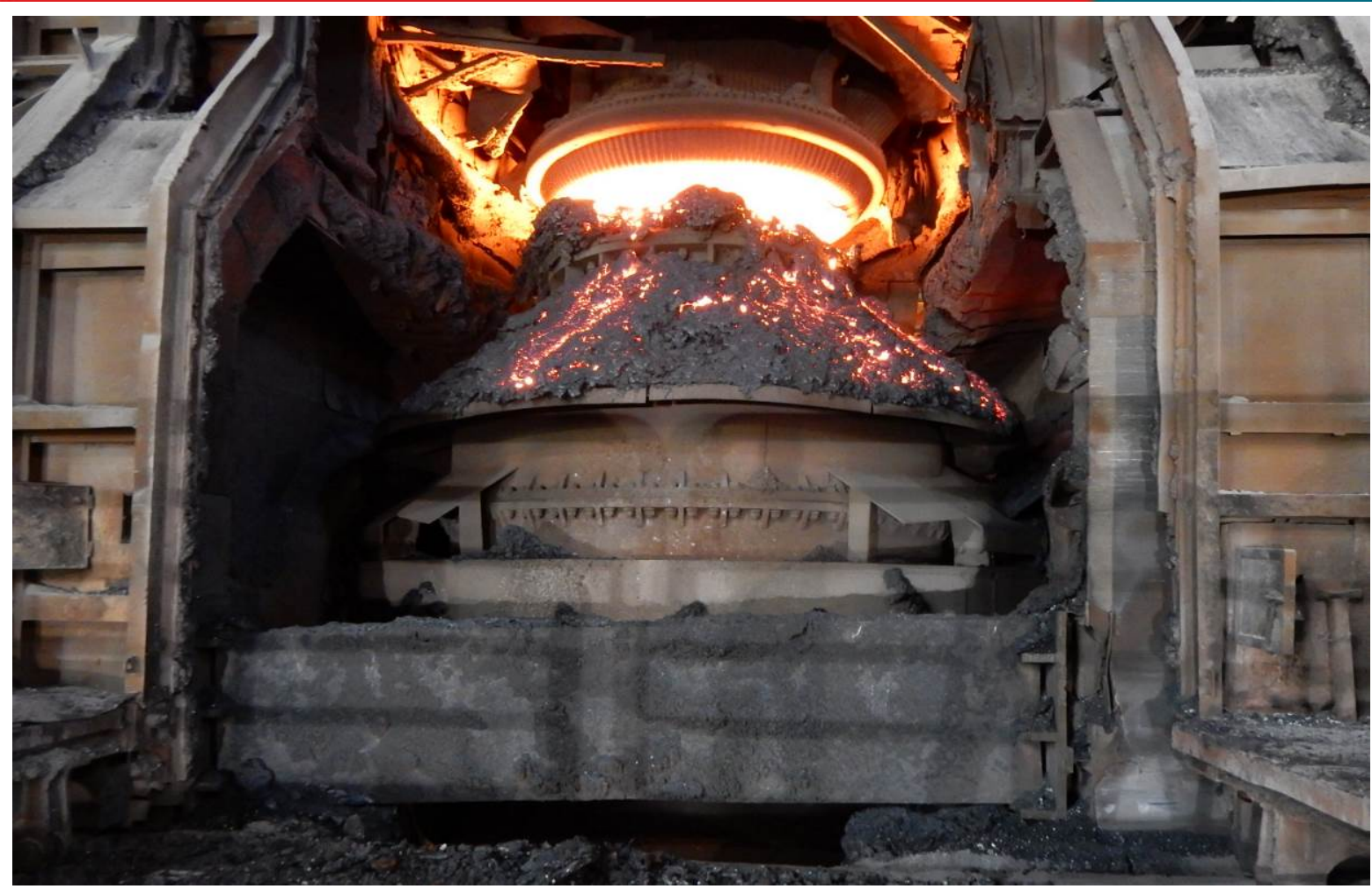

Figure 8: Converter during steel production

\section{CONCLUSION}

In the steelmaking shop of Aperam Timoteo the existing MRP-L converter has to be exchanged by a state of the art solution showing following design features:

- New trunnion ring with welded pins

- Converter with increased volume from $56 \mathrm{~m}^{3}$ to $62.2 \mathrm{~m}^{3}$, this is a plus of $11 \%$

- Maintenance free suspension system based on DANIELLA horizontal and lamella type vertical elements

- Maintaining the existing tilting drive, bearing size, bearing housings and dog house

- Minimizing pre-assembly activities by avoiding site welding due to flange connection of upper part of vessel shell

- Optimized slag shields

- Minimizing the total project time

The main equipment could be delivered in two major parts only. The lower converter vessel with fully assembled trunnion ring and suspension system and the upper part of the vessel shell which came along with a minimizing of the erection procedure and avoiding any site welding of the core equipment as well.

With these modifications all requirements from APERAM could be more than fulfilled. Together with a carefully planned pre-assembly and erection procedure done by Aperam together with Danieli it was possible to the reduce the total project time but in particular the site activities could be to almost halved and just 17 days after begin of erection, the cold commissioning could be achieved. 